be justified by cost-effectiveness as well as by the enhanced quality of life.

\section{References}

${ }^{1}$ Fuchs, V R, Who Shall Live? Health, Economics, and Social Choice. New York, Basic Books Inc, 1974.

${ }^{2}$ Mundth, E E, and Austen, W G, New England fournal of Medicine, $1975,293,13,75,124$

3 Spencer, F C, Isom, O W, and Glassman, E, Annals of Surgery, 1975, 180, 439.

${ }^{4}$ Miller, R R, American fournal of Cardiology, 1975, 35, 11.
5 Johnson, W D, and Kayser, K L, Annals of Thoracic Surgery, 1973, 16, 1. 6 Barnes, G K, et al, Circulation, 1975, 52, suppl No 2, p 118.

${ }^{7}$ English, M T, et al, Circulation, 1975, 52, suppl No 2, p 144.

${ }^{8}$ Rimm, A A, fournal of the American Medical Association, 1976, 236, 361.

' Wallwork, J, Potter, B, and Caves, P K, British Medical fournal, 1978, 2 1680.

10 Tokaro, T, Hultgren, H, and Detre, K, Circulation, 1976, 54, suppl No 3, p 107.

11 Working Group on Long-term Effects of Coronary Bypass Surgery, The Hague, 1-4 November 1977. Copenhagen, WHO Regional Office for Europe, 1978.

(Accepted 14 August 1979)

\title{
Improving medication compliance: a randomised clinical trial
}

\section{STAFFAN E NORELL}

British Medical fournal, 1979, 2, 1031-1033

\section{Summary and conclusions}

A medication monitor which recorded the date and hour each time a medicine bottle was opened was used to evaluate a programme for improving patients' compliance with their treatment. Eighty-two patients with glaucoma who had been prescribed pilocarpine eye drops three times daily to prevent visual loss were randomised into two groups. Both groups used the medication monitor during two 20 -day periods, but before the second period the experimental group were given an education and tailoring programme in an attempt to improve their compliance. Nine patients missed the second treatment period and were excluded from the analysis. The patients in the experimental group showed significantly improved compliance when compared with the control group. The numbers of missed doses were reduced by about half, as was the proportion of time that exceeded the eight-hour dose intervals.

Follow-up studies are needed to determine how long the improved compliance persists, but anyone considering setting up an education and tailoring programme should recognise the extent to which therapeutic efforts are wasted because of non-compliance.

\section{Introduction}

In recent years studies of patient compliance have directed attention to the patient's role in drug treatment. Diagnostic and therapeutic efforts are of little value unless the prescribed regimen is followed by the patient, and non-compliance has been recognised as "a major problem in our health care system."

Different strategies have been suggested to improve patients' compliance. These include efforts to increase the patient's knowledge and understanding of his disease and its treatment and attempts to integrate or "tailor" the regimen into the

\footnotetext{
Department of Social Medicine, Karolinska Institutet, Huddinge University Hospital, Huddinge, Sweden

STAFFAN E NORELL, MD, physician
}

patient's daily life. But little is known about the effectiveness of these measures in improving compliance, and Sackett et al have argued that such strategies should be evaluated in controlled trials. ${ }^{2}$ The cost-effectiveness of improving medication compliance has been discussed by Stason and Weinstein. ${ }^{3}$

Our aim was to evaluate an education and tailoring programme for patients with glaucoma in a randomised clinical trial based on objective and detailed information about the patients' drug taking.

\section{Patients and methods}

The series comprised patients treated with pilocarpine for chronic simple glaucoma at the eye clinic of Huddinge University Hospital. All had glaucomatous visual field defects, cupping of the optic disc, and raised intraocular pressures, and all were prescribed pilocarpine eye drops three times daily in an eye with visual acuity of at least 2/60. Data were collected from March 1977 to November 1978. A total of 82 patients, 45 men and 37 women, aged 56-90 (median 73) years met the criteria at the time of their entry into the study. They were stratified for age and randomly allocated to an experimental group or a control group.

The patients' behaviour in using the eye drops was studied with a medication monitor which recorded the date and hour each time the medication bottle was opened.

The monitor (fig 1) consisted of a plastic box with a holder for a $25-\mathrm{ml}$ medicine bottle. The holder was designed to protect the bottle and to facilitate replacement of the eyedropper cap. An elastic flap linked to a microswitch inside the box signalled to the electronic part of the monitor whether the cap was on or off. A sliding lid in the bottom of the monitor could be removed to exchange the bottle and battery but it was sealed when the monitor was given to the patients. The electronic system recorded information on whether or not the bottle had been opened during the last hour. When the monitor was connected to a separate read-out device this information, together with a time signal, was displayed on an electrocardiographic recorder.

Study periods-Recordings were made over three weeks between two visits to the eye clinic. The days of the visits were excluded, leaving a monitored record of 20 days for each patient. At the second visit to the clinic the patients in the experimental group underwent a 30-minute patient education and tailoring programme, and all patients then used the monitor to record their drug taking for a further 20 days.

Patient education-Basic information on the disease and its treatment was supplied by a tape-slide show and by leaflet. An ophthalmology assistant checked the patient's knowledge and understanding and re-emphasised insufficiently mastered information. The patients were encouraged to ask questions and discuss problems about their own medication. 


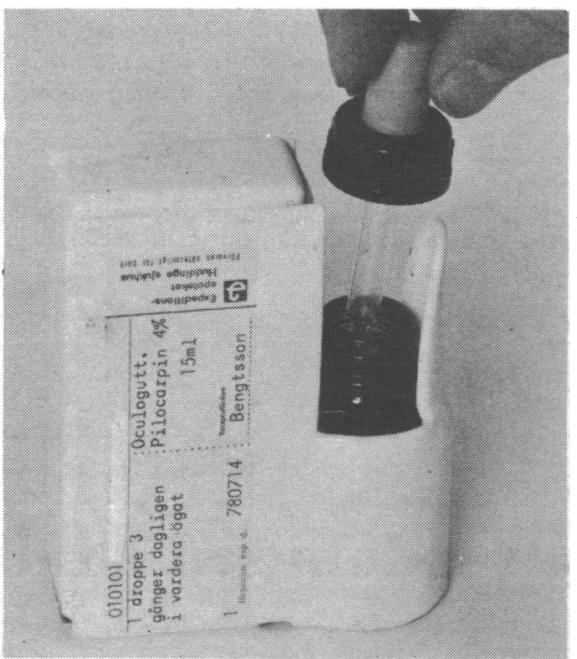

FIG 1 -Medication monitor with 25-ml eye-drop bottle.

Tailoring-Each patient was interviewed by the assistant to find out his or her everyday habits and determine suitable times, about eight hours apart, when medication could be fitted in with the patient's daily routines. Whenever possible the assistant suggested that the eye drops should be applied immediately before such routines and that the medication bottle should be kept where they were performed. The times and routines for medication were written on the leaflet for each patient.

Complete records for the two 20-day periods were obtained for 73 patients. The second monitor record was lost in nine cases-one patient suffered acute heart disease, two were admitted to hospital for long-term care, in two cases the monitor was lost or broken, and in four no record was obtained because the monitor battery was defective. The first and second records were compared in each patient in the experimental $(n=35)$ and control $(n=38)$ groups. Patients were not told the purpose of the monitor until we had finished collecting all the data. (Their informed consent to the study was then obtained, as approved by our local ethical committee.)

Analysis-If all the prescribed doses had been taken at equal intervals the interval should have been eight hours. For each patient the proportion of time in each test period that exceeded the eight-hour interval was determined. The difference between the first and second 20-day periods was described as a frequency distribution for each group. The groups were compared using a $t$ test and the difference between them was estimated. ${ }^{4}$ For each patient the number of missed doses in each test period was divided by the number of doses prescribed for that period $(3 \times 20=60)$, giving the proportion of missed doses. Again, the difference between the first and the second 20-day period was described as a frequency distribution for each group. The groups were compared using a $t$ test and the difference between them was estimated.4

\section{Results}

In the experimental group there was a $60 \%$ decrease in dose intervals of more than 11 hours during the second period, and dose intervals of less than six hours decreased by $61 \%$. Fig $2 a$ shows the change in frequency distribution of dose intervals in the experimental group. In the control group the frequency distribution of dose intervals was similar during both test periods (fig $2 b$ ).

During the first 20-day period the proportion of time that exceeded the eight-hour dose intervals and the proportion of missed doses were similar in the two groups (see table). In the second test period these variables decreased considerably in the experimental group but not in the control group.

The difference between the two groups in the change (between the first and second periods) in the proportion of missed doses for each patient was significant $(t=2.89 ; \mathrm{P}=0.004)$ and estimated at $9.0 \pm 6.1 \%$ (95\% confidence limits). The difference in the change in the proportion of time that exceeded the eight-hour dose intervals for each patient was also significant $(t=4.60 ; \mathrm{P} \simeq 0)$ and estimated at $12.9 \pm 5.5 \%$ (95\% confidence limits).
Time exceeding eight-hour dose intervals and missed doses in experimental and control group and among patients lost from study at second test period

\begin{tabular}{|c|c|c|c|}
\hline & $\begin{array}{c}\text { Test } \\
\text { period }\end{array}$ & $\begin{array}{l}\% \text { of time exceeding } \\
\text { eight-hour dose } \\
\text { intervals }\end{array}$ & $\begin{array}{l}\% \text { (and No) of } \\
\text { missed doses }\end{array}$ \\
\hline Experimental group $(n=35)$ & 1st & 22 & $10(217)$ \\
\hline Control group $(n=38) \quad \ldots$ & $\left\{\begin{array}{l}2 \mathrm{nd} \\
1 \mathrm{st}\end{array}\right.$ & $\begin{array}{l}13 \\
21\end{array}$ & $\begin{aligned} 6(120) \\
10(239)\end{aligned}$ \\
\hline $\begin{array}{l}\text { Patients lost at second test } \\
(\mathrm{n}=9)\end{array}$ & & 23 & $9(51)$ \\
\hline
\end{tabular}

\section{Discussion}

Our patients complied with their treatment to a greater extent than many other series of patients on long-term medication. ${ }^{5}$ Nevertheless, our results indicate that the programme of education and tailoring was effective in improving compliance. Missed doses were reduced to about half, as was the time that exceeded the eight-hour dose intervals. The number of short (under six hours) as well as long (over 11 hours) dose intervals decreased, indicating more regular spacing between the doses taken. Follow-up studies may show to what extent these changes in medication behaviour persist and whether the effectiveness of the treatment increases.
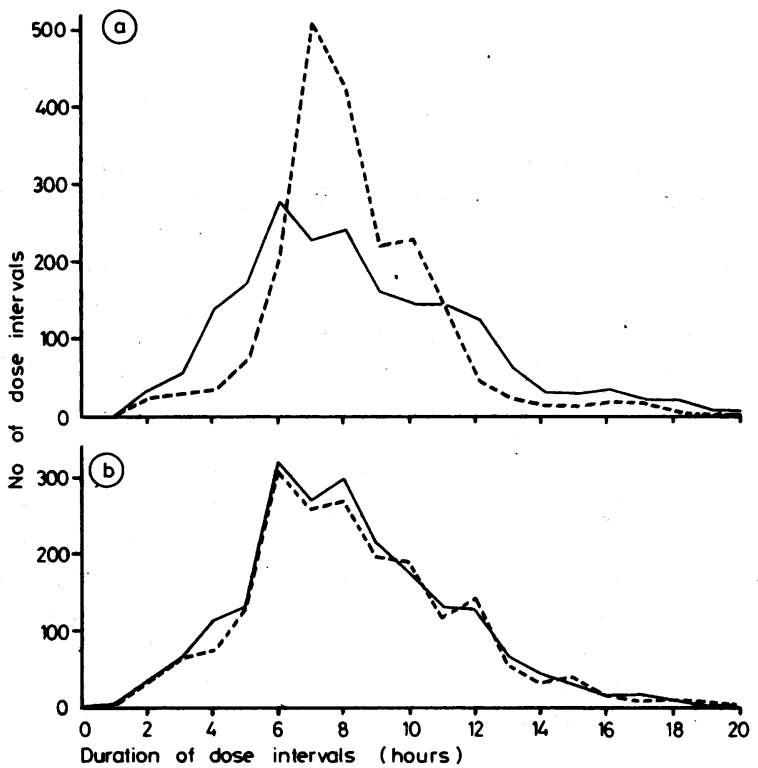

FIG 2-Frequency distribution of dose intervals during first and second (dotted line) 20-day periods for $(a)$ experimental group and $(b)$ control group.

Are these results applicable to daily practice or were they influenced by conditions peculiar to our study? The patients who were lost to the study showed similar compliance to those with complete records, and the doctor and nurse who saw the patients did not know which group they were in until the end of the second visit. The extra attention paid to the patients in the experimental group by the assistant was considered to be a part of the education and tailoring programme and would apply also to its use in routine practice. Patients who complied with their treatment regimen during the first test period were not excluded from the analysis of the results. The results would appear more favourable if they had been excluded, but this would not apply in routine practice unless there were a simple way of identifying these patients.

The programme we evaluated in the present trial included two major principles: patient education and tailoring. Providing the patient with basic information on his disease and its treatment may be essential for many reasons. The patient's knowledge of his own drug treatment is often insufficient and misconceptions 
and misinterpretations are common..$^{6-8}$ On the other hand, increased knowledge may not be sufficient to change a patient's behaviour over taking drugs. For example, a patient education programme for hypertension had no effect on compliance, though it did increase the patients' knowledge of the disease and its treatment. ${ }^{9}$ Similarly, pharmacist's instructions and an instruction card with information on the drug regimen did not increase compliance in patients for whom a 10-day course of penicillin was prescribed. ${ }^{10}$ The effect of such information may be limited by being presented in a form which is not easily understood by the patient. ${ }^{11}$ The tailoring principle that we also used was included in a more complex programme in patients with hypertension which resulted in increased adherence to the prescribed drug regimen. ${ }^{12}$

Further studies are needed to evaluate patient education and tailoring programmes for patients on different kinds of longterm medication. When considering the feasibility of introducing a patient education and tailoring programme in routine practice doctors should recognise the extent to which their diagnostic and therapeutic efforts are wasted because of nonadherence to the drug treatment prescribed.
I am indebted to Dr Per-Arne Granstrom and the staff of the eye clinic at Huddinge University Hospital for their co-operation.

\section{References}

1 Stewart, R B, and Cluff, L E, Clinical Pharmacology and Therapeutics, 1972 , 13, 463 .

${ }^{2}$ Sackett, D L, et al, American Heart fournal, 1977, 94, 666.

${ }^{3}$ Stason, W B, and Weinstein, M C, New England fournal of Medicine, 1977, 296, 732.

${ }^{4}$ Armitage, P, Statistical Methods in Medical Research, p 120. New York, Wiley, 1971.

${ }^{5}$ Sackett, D L, and Haynes, R B, editors, Compliance with Therapeutic Regimens. Baltimore, Johns Hopkins University Press, 1976.

6 Bain, D J G, Medical Education, 1977, 11, 347.

' Hellström, K, and Leijd, B, Läkartidningen, 1976, 73, 968.

${ }^{8}$ Hermann, F, American fournal of Hospital Pharmacy, 1973, 30, 155.

${ }^{9}$ Sackett, D L, et al, Lancet, 1975, 1, 1205.

${ }^{10}$ Linkewich, J A, Catalano, R B, and Flack, H L, Drug Intelligence and Clinical Pharmacy, 1974, 8, 10 .

${ }^{11}$ Ley, P, Jain, V K, and Skilbeck, C E, Psychological Medicine, 1976, 6, 599.

12 Haynes, R B, et al, Lancet, 1976, 1, 1265.

(Accepted 2 August 1979)

\title{
Bronchodilator effect of sodium cromoglycate and its clinical implications
}

\author{
J T N CHUNG, R S JONES
}

\section{Summary and conclusions}

The bronchodilator effect of sodium cromoglycate (SCG) solution was investigated. Twenty asthmatic children aged 6-15 years (mean 11.3) were examined and the action of SCG compared with that of salbutamol and placebo (water). SCG produced a significantly raised peak expiratory flow rate (PEFR) before exercise, which reached a maximum immediately after exercise. The bronchodilatation was sustained for up to four hours, when the PEFR was still significantly above the resting value. This effect was comparable in degree and duration with that of salbutamol. In contrast, placebo produced insignificant bronchodilatation before exercise but significant albeit short-lived bronchodilatation after exercise, which is the characteristic response of the asthmatic to a short period of exercise.

This powerful bronchodilator action of SCG and its equally potent inhibitory action on exercise-induced bronchoconstriction was achieved by administering the solution via an efficient nebuliser. In order to achieve maximum clinical effect the SCG must, therefore, be given in this form.

\section{Introduction}

Sodium cromoglycate (SCG) is now an established drug in the

\footnotetext{
Respiratory Unit, Alder Hey Children's Hospital, and the Institute of Child Health, University of Liverpool, Liverpool

J T N CHUNG, MB, DCH, research assistant, respiratory unit

R S JONES, MD, FRCP, consultant paediatrician, Alder Hey and Royal Liverpool children's hospitals
}

prophylactic treatment of asthma. It selectively suppresses the specific immunological pathways leading to the release of certain chemical mediators of immediate hypersensitivity and has been said to have no bronchodilator property. ${ }^{1}$ The inhibitory action of SCG on exercise-induced bronchoconstriction is well documented, but its bronchodilator properties are less well defined. Morton and Fitch ${ }^{2}$ in a report on the inhibition of exercise-induced bronchoconstriction by SCG powder found some bronchodilatation before the start of exercise but did not comment on it. Godfrey and König ${ }^{3}$ studied the inhibition of exercised-induced bronchoconstriction using various drugs and showed incidentally that there was an insignificant rise in peak expiratory flow rate (PEFR) after the inhalation of SCG powder at rest but a significant degree of bronchodilatation during exercise. Silverman and Andrea ${ }^{4}$ in a similar study of bronchoconstriction reported the enhancement of the bronchodilating action of exercise by prior inhalation of SCG powder. They commented that SCG could be used in place of bronchodilator aerosols for immediate effect.

We investigated the bronchodilator effect of SCG by using the solution, as we have found it to be superior to powder in its inhibitory action on exercise-induced bronchoconstriction. ${ }^{5} \mathrm{We}$ compared the action of SCG with that of salbutamol.

\section{Subjects and methods}

We studied 20 asthmatic children (three girls, 17 boys) aged 6-15 years (mean 11-3). Most were atopic subjects who reacted to skin tests with a variety of allergens and had a family history of atopy. Six also had eczema. Short exercise consisting of one minute of vigorous running on a flat corridor was performed on three separate days: after administration of salbutamol from an inhaler on one day, SCG solution on another, and placebo ( $4 \mathrm{ml}$ water) on a third day (these last two delivered by a mains-driven Wright nebuliser). The rate of flow of air through the nebuliser was $10-121 / \mathrm{min}$, and administration was continued until all the SCG solution had been nebulised. The dosage received by the subjects' lungs from one ampoule of solution is likely to have been appreciably higher than that received from one capsule 